\title{
Lung transplant outcomes: a review of survival, graft function, physiology, health-related quality of life and cost-effectiveness
}

\author{
S.M. Studer*, R.D. Levy", K. McNeil", J.B. Orens ${ }^{+}$
}

Lung transplant outcomes: a review of survival, graft function, physiology, healthrelated quality of life and cost-effectiveness. S.M. Studer, R.D. Levy, K. McNeil, J.B. Orens. C) ERS Journals Ltd 2004.

ABSTRACT: The success of lung transplantation has improved over time as evidenced by better long-term survival and functional outcomes. Despite the success of this procedure, there are numerous problems and complications that may develop over the life of a lung transplant recipient. With proper monitoring and treatment, the frequency and severity of these problems can be decreased. However, significant improvement for the overall outcomes of lung transplantation will only occur when better methods exist to prevent or effectively treat chronic rejection.

Eur Respir J 2004; 24: 674-685.

\begin{abstract}
*The University of Pittsburgh Medical Center, Division of Pulmonary, Allergy and Critical Care Medicine, Pittsburgh, PA, ${ }^{+}$Johns Hopkins Hospital, Baltimore, MD, USA, ${ }^{\#}$ St. Paul's Hospital and "British Colombia Transplant Society, Vancouver, BC, Canada.
\end{abstract}

Correspondence: J.B. Orens, Johns Hopkins Hospital, $1830 \mathrm{E}$ Monument St, 5th floor, Baltimore, MD 21205, USA.

Fax: 14109550036 ,

E-mail: Jorens@jhmi.edu

Keywords: Cost, function, lung transplantation, outcomes, quality of life, survival

Received: June 32004

Accepted: June 62004
Lung transplantation (LT) is now an established treatment option for patients with a wide variety of end-stage lung diseases. Although the early experience with LT in the 1960 s and 1970s yielded extremely poor results, since the 1980s the experience has been much more promising. This is, in part, due to the introduction of the immunosuppressive drug cyclosporin A, which paved the way for the first successful lung (heart-lung) transplant performed at Stanford University, USA in 1981. Shortly after the proven success of combined heart-lung transplantation (HLT), both single (SLT) and sequential double lung transplantation (DLT) became therapeutic options for selected candidates in the mid and late $1980 \mathrm{~s}$, respectively. Since then, $\sim 1,500$ lung transplants are performed annually worldwide, and this number is limited only by the lack of available donor organs. Despite the overall success of these procedures, there are still significant problems that limit both quality of life (QoL) and longterm survival. Some of these problems are common to recipients of all solid organ transplants. However, some are unique to LT.

When compared to liver and kidney transplants, the longterm outcomes of LT are worse (small bowel transplantation statistics are actually worse than LT: $76.9 \% 1-\mathrm{yr}$ mortality versus $77.4 \% 1 \mathrm{yr}$ mortality for LT, 58.8\% 3-yr mortality versus 59.3\% 3-yr mortality for LT) [1]. A number of factors appear to be responsible for this problem, but the most limiting issue is obliterative bronchiolitis (OB; the histological correlate of chronic rejection) and infection. Both chronic rejection and infection occur more commonly and earlier in lung allografts compared with all other solid organ transplants. The reason for the higher rate of rejection in lung allografts is not well understood. However, it is notable that, unlike other solid organ transplants (except small bowel), the lung allograft is in direct communication with the outside environment, thus leaving it susceptible to direct injury from inhaled foreign material and infection. Such nonimmunological injury may stimulate an immune response, setting into motion a cascade of events that ultimately leads to allograft rejection. Furthermore, as a consequence of the transplant procedure, in addition to having abnormal mucociliary clearance mechanisms, lung allografts lack innervation and lymphatic drainage, leading to impaired removal of foreign material, micro-organisms and secretions [2]. Beyond the exposures from the external environment, the lung is also under the same constant threat as other solid organ transplants from direct alloimmune rejection.

This review will address outcomes of LT including survival, function, physiological results, QoL and cost effectiveness.

Previous articles in this series: No. 1: Glanville AR, Estenne M. Indications, patient selection and timing of referral for lung transplantation. Eur Respir J 2003; 22: 845-852. No. 2: Boehler A, Estenne M. Post-transplant bronchiolitis obliterans. Eur Respir J 2003; 22: 1007-1018. No. 3: Knoop C, Haverich A, Fischer S. Immunosuppressive therapy after human lung transplantation. Eur Respir J 2004; 23: 159-171. No. 4: Kotloff RM, Ahya VN. Medical complications of lung transplantation. Eur Respir J 2004; 23: 334-342. No. 5: de Perrot M, Weder W, Patterson GA, Keshavjee S. Strategies to increase limited donor resources. Eur Respir J 2004; 23: 477-482. 


\section{Survival}

\section{Influence of pre-operative diagnosis}

An important factor affecting survival outcomes is the wide variety of disease states for which LT is performed. Each of these diseases is accompanied by a host of factors that directly impact on both short- and long-term survival outcomes. Patients with chronic obstructive pulmonary disease (COPD) have the best short- and long-term survival, whilst patients with idiopathic pulmonary fibrosis (IPF) and pulmonary hypertension fare less well. Thus, when assessing survival statistics, it is important to do so in relation to the underlying lung disease. Also of great importance is the disparity in survival for different underlying disease states whilst patients are waiting for transplantation. In this regard, patients with IPF are the most likely to die whilst waiting, whereas patients with COPD stand the best chance of surviving the potentially long time on the waiting list. Thus, it is important to view post-transplant outcomes in the context of the natural history of the disease. Having a solid understanding of these issues helps not only in deciding on the proper timing for transplantation for the individual patient, but also has implications for donor-organ allocation when faced with patients with different diseases.

\section{Influence of the type of surgical procedure}

Another observation that possibly impacts on survival is the type of transplant performed. In the most recent analysis of data from the International Society For Heart and Lung Transplantation (ISHLT) registry, there appears to be a small survival advantage for patients who have received DLT compared with SLT procedures (fig. 1) [3]. In a further analysis of the international registry data, MEYER et al. [4] demonstrated that the survival advantage of DLT procedures extended up to age $60 \mathrm{yrs}$ for recipients with COPD. Similar findings for patients with COPD were reported by the Washington University group, St. Louis, MO, USA, in a retrospective review of their experience over a 13-yr period [5]. Much speculation exists about why DLT would confer a long-term survival advantage, but one study suggests a decreased rate of bronchiolitis obliterans syndrome (BOS) in patients who have undergone DLT [6]. However, a problem with interpreting

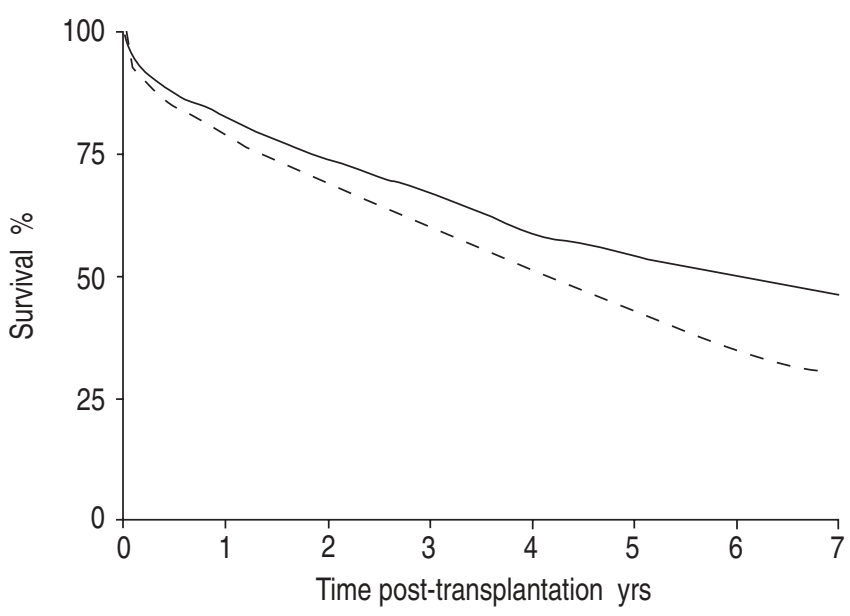

Fig. 1.- Actuarial survival for emphysema by procedure type from 1990-2001. Adapted with permission from ref [3]. ---: single lung transplantation $(\mathrm{n}=3,513) ; \stackrel{-}{-}$ : double lung transplantation $(\mathrm{n}=1,130)$. this finding, as highlighted by HADJILIADIS et al. [6], is the fact that development of $\mathrm{OB}$ in the transplanted single lung will probably lead to a larger decrease in forced expiratory volume in one second (FEV1; less pulmonary functional reserve), and also because native lung hyperinflation may impinge on allograft function. In any event, the potential advantage with DLT may be overshadowed by the potential benefit of helping twice as many patients with SLT. This issue is still being debated, in particular with relation to specific diseases. Aside from septic lung diseases that absolutely warrant DLT, debate still exists for primary pulmonary hypertension as to whether SLT, bilateral lung transplantation (BLT) or HLT is most appropriate. Similarly, in Eisenmenger's syndrome secondary to a simple septal defect, debate exists as to whether HLT or BLT/SLT with repair of the defect is optimal. The ISHLT registry data [3] show no difference in outcome between SLT and BLT for primary pulmonary hypertension, and there have been no direct comparisons of LT versus HLT in this group. Interestingly, for patients with Eisenmenger's syndrome associated with a ventricular septal defect, the ISHLT/United Network for Organ Sharing (UNOS) registry data [7] show better survival with HLT compared with BLT with closure of the defect. However, there are a number of papers supporting a role for BLT and defect closure to maximise the use of available donor organs [8-10].

\section{Survival benefit}

Although the success of LT can be assessed by several different outcome measures, survival has traditionally been the most important benchmark against which transplant procedures have been judged. Survival results for LT and HLT are tracked by the ISHLT/UNOS registry database. These data, compiled from a very large cohort of patients recorded over a decade, provide physicians with the necessary information to consider a potential recipient's "chances" following transplantation. The survival curve for LT, derived from accumulated data from 1990-2000, is shown in figure 2 [3]. The curve is characterised by an initial steep decline over the first year, followed by a slower but steady attrition over the ensuing years. Interestingly, the more recent experience demonstrates improvement in overall survival (fig. 3).

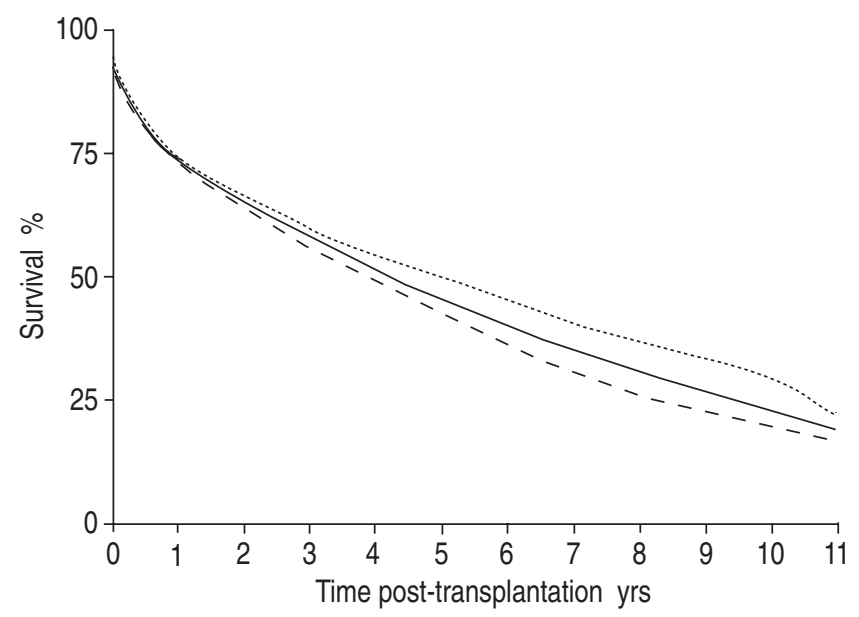

Fig. 2.-Actuarial survival for lung transplantation from 1990-2000. Adapted with permission from ref [3]. … bilateral/double lung transplantation $(n=6,448)$; ----: single lung transplantation $(n=7,798)$; and - : all lungs $(n=14,246)$. Double lung: half-life $=4.9$ yrs, conditional: half-life $=7.9$ yrs; single lung: half-life $=3.7 \mathrm{yrs}$, conditional: halflife $=5.9$ yrs; all lungs: half-life $=4.1$ yrs, conditional: half-life $=6.5 \mathrm{yrs}$. 


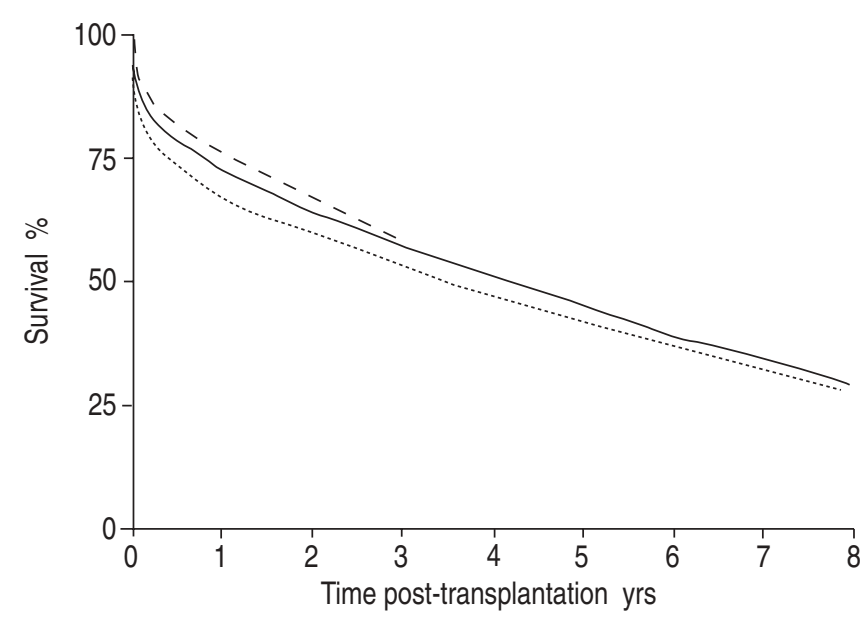

Fig. 3. - Actuarial survival for lung transplantation by era from 19882001. Adapted with permission from ref [3]. …: 1988-1992 ( $\mathrm{n}=2,093)$; -: 1993-1997 (n=5,999); and ---: 1998-2001 $(\mathrm{n}=5,595)$. Survival comparisons by era: 1988-1992 versus 1993-1997 ( $\mathrm{p}=0.007)$; 19881992 versus 1998-2001 ( $\mathrm{p}<0.0001) ; 1993-1997$ versus $1998-2001$ $(\mathrm{p}=0.003)$.

However, this improvement is solely as a result of reduced mortality during the peri-operative period, with little change in the slope of the long-term survival curve. Early results were affected by a steep learning experience, particularly with regard to surgical technique, peri-operative management, antimicrobial prophylaxis and recipient selection. Over time, not only have treatment regimens been changed and refined, but the characteristics of donors and recipients chosen have also evolved. As the difficulty in obtaining donor organs has increased, the limits of donor acceptability have been extended. In particular, donor age has increased over the years, and this may have significant implications for posttransplant survival.

Despite improvement in the peri-operative survival, over the long-term the slope of the survival curve continues to show the same slow attrition rate reflecting the problem of chronic rejection, for which there remains no effective therapy. This observation is disappointing in view of the ever broadening range of immunosuppressive agents available, as well as improved understanding of pharmacokinetic and pharmacodynamic principles related to their use.

There are a number of major complications that frequently arise following LT that, unfortunately, commonly lead to significant morbidity and mortality (table 1). In addition to these, a litany of other problems may also have significant impact on outcomes, including cardiovascular and gastrointestinal complications, as well as malignancy.

Data from the ISHLT registry show that infection is the leading cause of death in the first post-transplant year [3]. Infection tends to be a pervasive problem that may occur as a primary or secondary process, following significant surgical complications (excessive bleeding, vascular and airway

Table 1.-Potential life-threatening complications following lung transplantation

\section{Complication}

Ischaemia reperfusion injury

Primary graft failure

Anastamotic dehiscence

Infection

Rejection (acute and chronic) anastamotic complications, etc.) and primary graft dysfunction/severe ischaemia-reperfusion injury. Recipients with certain diseases pose a much greater risk for postoperative complications than others. For instance, patients with cystic fibrosis are at higher risk for peri-operative infection as a result of pre-transplant chronic sino-pulmonary infections. Complex congenital heart disease patients with multiple previous corrective procedures are at high risk of bleeding during the transplant procedure $[8,11]$. Patients with severe pulmonary hypertension treated with SLT are at an increased risk of severe ischaemia-reperfusion injury and may require prolonged post-operative mechanical ventilation [10]. Similarly, recipients of older donor lungs ( $>50$ yrs) that incur longer ischaemic times are also at increased risk of early and late graft dysfunction $[3,13]$. Despite this, in the current era, it is reasonable to expect 1-yr survival figures of $80-90 \%$ in uncomplicated recipients receiving "good" donor organs.

Beyond the first year, infection remains a major cause of morbidity and death. Several factors lead to the ongoing risk for infection, including the need for lifelong immunosuppression, abnormal airway clearance mechanisms, exposure of the allograft to the external environment and, therefore, to a host of potential pathogens, as well as OB. OB, the histological hallmark of chronic allograft rejection, and its clinical correlate BOS, occurs in $\leqslant 70 \%$ of recipients by 5 yrs after LT [14]. This is the leading cause of death in the long term $(>1 \mathrm{yr})$. Once $\mathrm{OB}$ is established, infection becomes the common final pathway leading to death in many of these patients.

As noted previously, the overall outcomes of LT must be assessed relating post-transplant outcomes to prospects without transplantation (so called "waiting list" mortality). Patients with IPF, cystic fibrosis and primary pulmonary hypertension have a higher mortality on the waiting list than patients with uncomplicated COPD or congenital heart disease. With a clear understanding of waiting-list mortality, it is feasible to develop models to assess the survival benefit for LT, and, indeed, these models may be important in determining appropriate organ-allocation systems. For instance, in a European database study [15], patients with pulmonary fibrosis and cystic fibrosis experienced a benefit from transplantation (compared with no transplant) at 55 and 90 days, respectively, whereas those with emphysema benefited by day 260 . However, conflicting data were derived from the ISHLT registry [16], where a survival benefit could not be established for COPD, stimulating some debate about the utility of LT for this disease. The lack of agreement presumably relates to characteristics of the study populations, as well as possibly to the retrospective study designs. Thus, post-transplant outcomes must be interpreted in the light of prognosis without transplantation so that patients can be counselled appropriately, as well as for deriving a reasonable approach for allocating organs in the most judicious fashion.

\section{Causes of morbidity and mortality following lung transplantation}

Morbidity and mortality following LT can be considered in the context of time periods. The morbidity and mortality encountered in the first year are related to events occurring during the transplant procedure and the post-operative phase (initial 30 days), and reflect the obligatory requirement for high levels of immunosuppressive therapy during the initial 12 months. Issues encountered subsequent to this relate principally to the inevitable onset of BOS and the complications of long-term immunosuppression, particularly the risk of infection. 
Table 2. - Adult lung transplant recipients: cause of death (January 1992-June 2002)

\begin{tabular}{|c|c|c|c|c|c|}
\hline Cause of death & 0-30 days ${ }^{\#}$ & 31 days $-1 \mathrm{yr}^{\top}$ & $>1 \mathrm{yr}-3 \mathrm{yrs}^{+}$ & $>3-5 \mathrm{yrs}^{\S}$ & $>5 \mathrm{yrs}^{f}$ \\
\hline Bronchiolitis & $5(0.5)$ & $74(5.5)$ & $313(28.6)$ & 185 & $142(31.1)$ \\
\hline Acute rejection & $46(4.9)$ & $27(2.0)$ & $21(1.9)$ & $4(0.7)$ & $2(0.4)$ \\
\hline Lymphoma & $1(0.1)$ & $44(3.3)$ & $23(2.1)$ & $9(1.6)$ & $18(3.9)$ \\
\hline Malignancy, other & & $27(2.0)$ & $52(4.7)$ & $43(7.5)$ & $40(8.8)$ \\
\hline CMV & $1(0.1)$ & $56(4.2)$ & $17(1.6)$ & $4(0.7)$ & $2(0.4)$ \\
\hline Infection, non-CMV & $220(23.5)$ & $521(38.7)$ & $284(25.9)$ & $113(19.8)$ & $79(17.3)$ \\
\hline Graft failure & $286(30.5)$ & $236(17.5)$ & $175(16.0)$ & $99(17.3)$ & $58(12.7)$ \\
\hline Cardiovascular & $108(11.5)$ & $58(4.3)$ & $36(3.3)$ & $24(4.2)$ & $21(4.6)$ \\
\hline Technical & $78(8.3)$ & $37(2.8)$ & $12(1.1)$ & $1(0.2)$ & $2(0.4)$ \\
\hline Other & $192(20.5)$ & $265(19.7)$ & $163(14.9)$ & $90(15.7)$ & $92(20.2)$ \\
\hline
\end{tabular}

Data are presented as $\mathrm{n}(\%) . \mathrm{CMV}$ : cytomegalovirus. ${ }^{\#}: \mathrm{n}=937 ;{ }^{\top}: \mathrm{n}=1,345 ;{ }^{+}: \mathrm{n}=1,096 ;{ }^{\S}: \mathrm{n}=572 ;{ }^{f}: \mathrm{n}=456$; Adapted with permission from [17].

\section{Causes of mortality}

30-day mortality. Graft failure (either "primary" or "other") accounts for $30.5 \%$ of the early mortality (table 2) [17]. Primary graft failure is ascribed to poor function of the allograft, caused by the combined processes of organ procurement, implantation and reperfusion, the so-called "ischaemiareperfusion injury". If severe, this may progress to diffuse alveolar damage and death. Nonspecific graft failure is difficult to define, and represents the diagnosis assigned when the cause of early allograft failure is either multifactorial and/or not subject to post mortem confirmation. Factors, such as significant operative and peri-operative bleeding, pulmonary venous anastamotic complications, ventilator-induced barotrauma, and the inevitable complication by infection in all these situations, may all contribute either singly or in combination to allograft dysfunction and failure, and consequent death. Acute rejection accounts for only $4.9 \%$ of early deaths and is, in the modern era of transplantation, a very uncommon cause of mortality.

1-yr mortality. For those patients surviving the peri-operative period, the major cause of death in the first year is infection. This may occur in the setting of a damaged allograft, which has "limped along" for the first few months, or may reflect the highdose immunosuppression given during this period. Communityacquired respiratory infections are common in these patients, and, if not promptly recognised, investigated and treated, they will progress rapidly, leading to either irreversible allograft injury and/or death.

In addition to infection, post-transplant lymphoproliferative disorders also reflect high-dose immunosuppression, and, as a consequence, these disorders are a significant cause of morbidity and mortality in the first 12 months. This was particularly evident in the early era of transplantation, when monoclonal antibody induction therapy (e.g. OKT3) was used more widely.

Longer-term (>1 yr) mortality. Obliterative Bronchiolitis/ Bronchiolitis Obliterans Syndrome. Of the lengthy list of potential problems that may develop following LT, OB/BOS remains the true "Achilles heel" for this procedure. OB is the major contributor to both long-term mortality and morbidity in LT patients [14, 18]. This condition manifests as fixed airflow obstruction and recurrent respiratory infection. Infection is the usual cause of death in these patients. Bronchiectasis usually accompanies the obliterative changes and pre-disposes to infection with gram-negative organisms (particularly Pseudomonas), and organisms such as nontuberculous mycobacteria and Aspergillus. Once established, OB/BOS tends to have an unrelenting progressive course with a $40 \%$ chance of death over 2 yrs following the diagnosis. OB/BOS is reviewed in great detail in other sections of this series.

Malignancy. Long-term survivors are at increased risk of malignancy reflecting the impact of long-term immunosuppression (table 3). In addition, older age and underlying disease states (e.g. smoking-related COPD, pulmonary fibrosis) add to this risk. The outcome for LT patients with solid tissue malignancies is, in most cases, extremely poor.

\section{Causes of morbidity}

Morbidity associated with the transplant surgery. The surgery itself is associated with pain and discomfort. This is often more severe and prolonged where a thoracotomy or clam-shell incision has been used, as opposed to a sternotomy. In addition, post-thoracotomy neuralgia can be associated with considerable and prolonged pain, often necessitating the use of specific therapy (anti-convulsant and/or tricyclic antidepressant drugs) for control. These medications themselves then add to the risks of drug interactions and side-effects (tables 4 and 5).

The different procedures associated with HLT and LT (SLT or BLT) has individual risks and associated morbidity. There is an obligatory requirement for cardio-pulmonary bypass (CPB) in HLT (and in some LTs). The morbidity associated with $\mathrm{CPB}$ is well recognised. In particular, $\mathrm{CPB}$ necessitates anticoagulation, which increases the risk of perioperative bleeding.

All forms of LT are associated with a risk of mediastinal nerve injuries. The phrenic nerves may be damaged, leading to diaphragmatic paralysis. In HLT, there is the additional risk of damage to the vagus and, occasionally, left recurrent

Table 3.-Malignancy post-lung transplantation for adults. Cumulative prevalence in survivors (follow-ups: April 1994June 2002)

\begin{tabular}{lcc}
\hline Malignancy & 1-yr survivors & 5-yr survivors \\
\hline No malignancy & $5104(96.1)$ & $886(86.9)$ \\
Malignancy (all types combined) & $209(3.9)$ & $134(13.1)$ \\
Malignancy type & & \\
$\quad$ Skin & 44 & 61 \\
Lymph & 109 & 21 \\
Other & 35 & 32 \\
Lymph+skin & & 3 \\
Lymph+other & & 5 \\
Skin+other & 21 & 2 \\
Type not reported & & 10 \\
\hline
\end{tabular}

Data are presented as $\mathrm{n}(\%)$. Adapted with permission from [17]. 
Table 4.-Post-lung transplant morbidity for adults. Cumulative prevalence in survivors within $1 \mathrm{yr}$ post-transplant (follow-ups: April 1994-June 2002)

\begin{tabular}{lc}
\hline Outcome & $\leqslant 1 \mathrm{yr}$ \\
\hline Hypertension & $49.4(5157)$ \\
Renal dysfunction & $25.0(6234)$ \\
$\quad$ Abnormal creatinine $<2.5 \mathrm{mg} \cdot \mathrm{dL}^{-1}$ & 14.8 \\
Creatinine $>2.5 \mathrm{mg} \cdot \mathrm{dL}^{-1}$ & 8.3 \\
Chronic dialysis & 1.9 \\
Renal transplant & 0.0 \\
Hyperlipidaemia & $15.2(5385)$ \\
Diabetes & $18.6(5100)$ \\
Bronchiolitis obliterans & $9.9(4792)$
\end{tabular}

Data are presented as \% (n). Adapted with permission from [17].

Table 5. - Post-lung transplant morbidity for adults. Cumulative prevalence in survivors within 5 yrs post-transplant (follow-ups: April 1994-June 2002)

\begin{tabular}{lc}
\hline Outcome & $\geqslant 1 \mathrm{yr}$ \\
\hline Hypertension & $86.5(931)$ \\
Renal dysfunction & $38.3(1025)$ \\
$\quad$ Abnormal creatinine $<2.5 \mathrm{mg} \cdot \mathrm{dL}^{-1}$ & 20.2 \\
Creatinine $>2.5 \mathrm{mg} \cdot \mathrm{dL}^{-1}$ & 13.7 \\
Chronic dialysis & 3.4 \\
$\quad$ Renal transplant & 0.9 \\
Hyperlipidaemia & $43.4(1019)$ \\
Diabetes & $27.8(907)$ \\
Bronchiolitis obliterans & $36.0(702)$ \\
\hline
\end{tabular}

Data are presented as \% (n). Adapted with permission from [17].

laryngeal nerve. This risk is increased when transplantation is performed in the setting of previous mediastinal surgery (e.g. complex congenital heart disease), where adhesions add significant difficulty to the mediastinal dissection. Vagalnerve injuries often result in delayed gastric emptying with profound nausea, leading to compromised nutrition and intolerance of medications.

Morbidity associated with allograft dysfunction. Significant allograft dysfunction will impose morbidity at any stage of transplantation, by directly causing shortness of breath and delaying rehabilitation, and, indirectly, by increasing the risk of respiratory infection. In long-term survivors, QoL generally reflects lung function. Lung function is reduced with the onset of BOS. With increasing severity of BOS, QoL is commensurately reduced, and the risk of developing infection is increased [14]. Both factors contribute significantly to the morbidity experienced by long-term survivors.

Morbidity associated with the underlying disease. The underlying disease may have effects at different stages posttransplant. Patients with complex congenital heart disease are at increased risk of bleeding during and immediately after the transplant [11]. Patients with severe pulmonary hypertension treated with SLT are at increased risk of ischaemia-reperfusion injury and/or right ventricular dysfunction [12]. Both occurrences add to the risk of morbidity and mortality in the peri-operative period.

SLT for emphysema may be associated with native lung hyperinflation. In the immediate post-operative phase, this may manifest as intrathoracic tamponade, necessitating differential ventilation to allow deflation of the emphysematous lung. In some extreme cases where a sternotomy approach has been used, delayed closure of the chest has been necessary.

In the longer term, hyperinflation of the native emphysematous lung may complicate allograft dysfunction and contribute to loss of lung function. Native lung volume reduction has been employed successfully in this setting, with documented improvements in dynamic lung function tests and exercise tolerance [19].

SLT has been associated with morbidity from infection in the native lung. This includes acutely acquired infection (pneumonia, etc.), as well as more chronic infections, such as tuberculosis and aspergillosis, which may have been present within the native lung at the time of transplant. Patients may present late in this situation, as the native lung does not usually contribute significantly to either lung function or gas exchange. Shortness of breath may, therefore, not be perceived, and respiratory infection may not be evident to the patient until systemic symptoms manifest.

A number of the diseases leading to transplant have direct implications for post-transplant outcomes. The septic lung diseases have an increased risk of recipient-derived bacterial infection post-transplant [20]. Cystic fibrosis with its multisystem effects, imposes considerable risks for morbidity, in terms of pancreatic function (nutrition and diabetes) and gastrointestinal function (distal intestinal obstruction, unreliable drug absorption).

Primary disease recurrence. Although generally not considered a problem for the majority of lung diseases transplanted, the risk of disease recurrence in the allograft may impair long-term function and outcomes for some transplant recipients. There are numerous case reports and one multicentre retrospective study [21] documenting the recurrence of primary lung disease. The multicentre study included a review of 1,394 transplant recipients and found a recurrence of disease rate of $1 \%$. Diseases that were pathologically proven to recur (with recurrence rates in parentheses) included as follows: sarcoidosis $(35 \%, n=26)$, lymphangioleiomyomatosis $(10 \%, \mathrm{n}=21)$, Langerhans cell histiocytosis $(25 \%, n=4)$, talc granulomatosis $(50 \%, n=2)$, diffuse panbronchiolitis $(100 \%, \mathrm{n}=1)$ and pulmonary alveolar proteinosis $(100 \%, n=1)$. Sarcoidosis is the most common disease reported to recur and was usually diagnosed incidentally.

In most cases, primary disease recurrence has not resulted in major limitations in success of the transplant, and, except for recurrence of bronchoalveolar cell carcinoma, no patient has been reported to die as a direct result of disease recurrence. However, as rates of chronic lung rejection decrease and overall survival rates improve, the impact of primary pulmonary disease recurrence may become more significant.

Morbidity associated with drug therapy. Much of the morbidity encountered in long-term survivors of LT is related to drug side-effects (tables 3 and 4). Of particular importance, in this respect, are those issues associated with the immunosuppressive drugs. The immunosuppression itself is a direct cause of morbidity and mortality through its association with infection and malignancy. In addition, each of the immunosuppressive agents is associated with considerable potential morbidity. In this respect, calcineurin inhibitors (renal dysfunction/failure, hypertension, neurotoxicity, etc.) and steroids (osteoporosis, adrenal suppression, weight gain, etc.) are the major culprits.

Functional outcomes. Functional outcomes after LT can be assessed by several parameters, including physiological variables such as pulmonary function tests and exercise tests, the ability to perform activities, employment status, need for re-hospitalisation, as well as the recurrence of the 
original lung disease. These parameters are described in further detail as follows. 1) Activity level: data from the ISHLT registry [3] suggests that $>80 \%$ of survivors at 1,3 and 5 yrs post-lung transplant report no activity limitations. Approximately 15\% require some assistance and a small percentage require total assistance with activities at those same time points. 2) Employment: despite the excellent outcomes from an activity standpoint, only $20 \%$ of recipients work full-time at $1 \mathrm{yr}$, and $\sim 30 \%$ work full-time at 5 yrs post-transplantation. An additional 5-10\% of lung transplant recipients work part-time at 1 and 5 yrs posttransplantation. Factors other than allograft function and overall health, such as loss of eligibility for governmentsponsored insurance in those who return to work, may affect reported employment rates. Hence, there are limitations to using post-transplant employment as a bench mark for functional outcome. 3) Re-hospitalisation: although functional outcomes are good, re-hospitalisation post-transplant is close to $65 \%$ within the first year, and remains $\sim 45 \%$ between 4 and 5 yrs post-transplant [3]. Most of these hospitalisations are for episodes of rejection or infection. 4) Physiological and functional outcomes: this section provides an overview of the physiological and functional outcomes following LT that are of greatest relevance to the clinical setting. For more detailed information, the reader is referred to the recent European Respiratory Monograph chapter entitled "Effects of Transplantation on Lung and Exercise Physiology" by Schulman and EsTENNE [22].

LT affords a unique opportunity to examine the effects of denervation on organ function, and, hence, has implications for the understanding of normal physiological processes. Physiological data derived from human LT recipients must be interpreted cautiously. However, since other conditions related to transplantation, such as chronic debilitating preoperative illness, medications and graft rejection, may have important confounding effects on graft function.

\section{Pulmonary denervation}

The surgical techniques of LT involve complete transection of the pulmonary autonomic nerves at the level of the distal trachea in the case of HLT, and at the level of the major bronchi in isolated and sequential BLT. Whether pulmonary reinnervation occurs over time in humans has not been directly studied. However, it would be anticipated that complete reinnervation would be unlikely in the context of human allotransplantation since no attempt is made to approximate nerve sheaths, which may vary substantially in anatomic position in donor and recipient structures. Indirect evidence for the persistence of denervation in human LT recipients has been derived from the observation of bronchial hyperresponsiveness to inhaled methacholine in these patients [23-27]. This has been hypothesised to be the result of denervation hypersensitivity of muscarinic receptors. Furthermore, HLT recipients studied for 36 months post-operatively show a markedly decreased cough response to inhalation of nebulised distilled water, despite preservation of the laryngeal cough response, providing further evidence for the persistence of pulmonary denervation [28].

\section{Control of breathing}

Resting minute ventilation, tidal volume, respiratory frequency and mean inspiratory flow rate are normal after HLT [29, 30]. Furthermore, HLT recipients have normal ventilatory drive during quiet breathing [31, 32]. These findings suggest that pulmonary neurogenic mechanisms play little, if any, role in the regulation of resting ventilation.

During sleep, SHEA et al. [30] found the level, pattern and variability of breathing during sleep in HLT recipients to be similar to normal subjects. Furthermore, there was no evidence for sleep-disordered breathing or nocturnal desaturation in the transplant recipients. In contrast, SANDERS et al. [33] reported that HLT recipients tend to have a more rapid breathing frequency than normal subjects during sleep. However, to what extent the presence of restrictive ventilatory defects could account for these findings could not be ascertained in this latter study.

The preservation of an essentially normal level and pattern of ventilation in the presence of chronic pulmonary denervation suggests that pulmonary neural mechanisms are relatively unimportant in the normal regulation of these activities during relaxed wakefulness and sleep.

Although the level of ventilation at rest is normal in healthy HLT recipients, there is evidence for hyperventilation during exercise $[32,34,35]$. The explanation for exercise hyperventilation is unknown; however, it may reflect an inadequate cardiocirculatory response to exercise associated with low mixed venous oxygen saturation and high mixed venous partial pressure of carbon dioxide tension $\left(\mathrm{PCO}_{2}\right)$ [34].

\section{Gas exchange}

Regional pulmonary blood flow normally decreases in response to local alveolar hypoxia, a phenomenon known as hypoxic pulmonary vasoconstriction. The precise mechanisms regulating hypoxic pulmonary vasoconstriction are uncertain. However, two possibilities exist. The first is that hypoxic pulmonary vasoconstriction is neurally regulated via the autonomic nervous system. Alternatively, hypoxic pulmonary vasoconstriction could result from local factors responsible for vasoregulation, such as chemical mediators. As such, pulmonary denervation resulting from LT represents an interesting model with which to evaluate the relative importance of these two postulated mechanisms.

Following human HLT, RoBIN et al. [36] observed intact hypoxic pulmonary vasoconstriction, and concluded that neural mediation, although perhaps important for modulating its intensity, is not essential for the phenomenon of hypoxic pulmonary vasoconstriction.

Several studies have reported normal levels of dead space ventilation at rest and during exercise after successful HLT $[30,37]$. This is not surprising, since the distribution of both ventilation and perfusion have been shown to be normal in HLT recipients with pulmonary denervation, at least in the resting state [38]. After SLT for obstructive lung disease, $\sim 80 \%$ of both the ventilation and the perfusion are distributed to the transplanted lung [39]. Although a similar pattern of perfusion distribution is seen in restrictive SLT recipients, the ventilation to the transplanted lung in these latter patients is only $60-70 \%$ of the total $[39,40]$. In the presence of acute rejection of a single lung graft, blood flow may be redistributed away from the transplanted lung [40], which can result in substantial ventilation-perfusion mismatching and, importantly, hypoxaemia, especially in patients with underlying pulmonary vascular disorders [41].

Within 8 weeks after uncomplicated HLT, gas exchange tends to be normal [37]. Diffusing capacity for carbon monoxide $(D \mathrm{~L}, \mathrm{CO})$ has been variably reported as being normal $[32,42]$ or mildly reduced $[43,44]$ in HLT recipients. Recipients have normal oxygenation 3 months after DLT [45]. After SLT, oxygenation improves substantially from 
pre-operative values [45]; however, a mildly elevated alveolararterial oxygen difference in these latter patients is probably the result of the contribution to gas exchange provided by the remaining diseased native lung.

Oxygenation remains normal in HLT recipients during peak incremental [32, 46] and steady-state [37] exercise. Furthermore, the change in $D \mathrm{~L}, \mathrm{CO}$ with increasing levels of exercise in these patients is similar to that observed in normal subjects [44]. Oxygen saturation with peak incremental exercise is also normal in DLT recipients, as well as in SLT recipients with underlying obstructive lung disease [46-48]. However, mild exercise desaturation may be seen in SLT recipients with restrictive parenchymal or pulmonary vascular disorders $[39,46]$.

\section{Airway function}

Following HLT, GLANVILLE et al. [24] reported a combination of nonspecific bronchial hyperresponsiveness, absence of bronchoconstriction with respiratory manoeuvres and the absence of bronchodilatation with deep inspiration following induced bronchoconstriction, and postulated that the results were consistent with a lack of normal pulmonary innervation. Other groups have also reported evidence for moderate bronchial hyperresponsiveness to methacholine [23, 26, 27, 49] and histamine [26] challenge after HLT and LT. This hyperresponsiveness has been observed in the absence of substantial transbronchial biopsy evidence for airway inflammation [26, 27], and has been found to be stable over time [25]. These patients do not exhibit exercise-induced bronchoconstriction [50], and do not generally present with a clinical syndrome suggestive of asthma. Several investigators have proposed that enhanced bronchial responsiveness to methacholine is a result of denervation hypersensitivity of airway smooth muscle muscarinic receptors [25, 27, 49]. In contrast, HERVE et al. [51] did not find increased nonspecific bronchial responsiveness to methacholine or isocapnic dry air hyperventilation in HLT and DLT recipients with normal lung histology. The explanation for these differing findings is not apparent. Although the presence or development of bronchial hyperresponsiveness to a variety of nonspecific stimuli (methacholine, hypotonic saline, hyperventilation, exercise) has been reported by a number of centres to be a predictor for the subsequent development of $\mathrm{OB}$ in $\mathrm{LT}$ recipients, this finding has not been universal nor of sufficient predictive value to be clinically useful as a screening test for this condition $[23,25,42,50-52]$.

\section{Ventilatory sensation}

Several lines of investigation have suggested that pulmonary afferent neural information can play a direct role in the mediation of dyspnoea [53-56]. Alternatively, vagal mechanisms may contribute to dyspnoea indirectly, by modulating the pattern of ventilation and, hence, the level of central respiratory output and pattern of respiratory muscle activation [57]. Pulmonary denervation, an inevitable outcome with LT, provides a unique opportunity to study the role of pulmonary autonomic nerves in the mediation of dyspnoea in humans.

BANNER et al. [23] reported that HLT recipients undergoing methacholine bronchial provocation testing experienced a "tight" sensation in the chest, associated with the feeling that it was difficult to take a deep breath, similar to the sensations commonly reported by normal subjects undergoing bronchial challenge testing. The investigators concluded that pulmonary innervation is not essential for this sensation. However, they did point out that their findings do not rule out a possible important role for receptors in the remaining native trachea above the level of the anastomosis. The sensation of breathlessness during exercise [32, 58], as well as detection of inspiratory resistive loads [59], is also normal following HLT. These observations indicate that pulmonary neurogenic mechanisms do not appear to contribute significantly to the perception of breathlessness in normal humans.

\section{Pulmonary function}

At the time of donor identification, much attention is devoted to assuring that the physical size match between donor and recipient thoraces is fairly close. However, as a result of limited donor availability, precise donor-to-recipient size matching is not always feasible. Fortunately, the thorax has remarkable plasticity, and the rib cage and diaphragm are able to easily compensate for smaller donor organs. Transplant teams have, in general, tried to avoid utilising oversized organs, since post-operative compressive atelectasis with poor ventilation in a patient with already impaired host defenses could result in localised infectious complications. In the situation of substantial size discrepancies between donor and recipient, several centres have had success with pneumoreduction procedures to the donor lungs at the time of transplant [60].

Following LT, after initial falls, post-operative values for total lung capacity (TLC) approach the recipient's predicted value at 1 yr post-transplant, irrespective of the size of the donor lungs, suggesting that characteristics of the chest wall are the major determinants of post-operative lung volume, and not the donor lung size or compliance $[61,62]$. The stable pulmonary function observed after HLT has been reported to be consistent with a mild restrictive ventilatory pattern [43]. Lung allograft compliance has been found to be normal, with a low TLC best correlated with maximum inspiratory mouth pressure, suggesting that the restriction early post-transplant could be related to respiratory muscle weakness (from malnutrition, deconditioning or steroid therapy) or phrenic nerve dysfunction [42]. Lung volumes after SLT will depend, to an extent, on the physiological properties of the remaining native lung. In SLT recipients with pulmonary fibrosis, vital capacity increased from a mean pre-operative value of $43 \%$ predicted to $69 \%$ predicted at 1 yr [40]. Virtually all of the improvement was seen at 3 months post-operatively, after which, plateaus were seen in most patients. In the case of SLT for obstructive lung diseases, mild elevations in TLC persist, albeit substantially reduced from pre-operative values [63] and FEV1 is expected to rise to $50-57 \%$ predicted [64-67]. LEVINE et al. [68] reported no substantial functional advantage to performing a right, as compared with a left, SLT in patients with obstructive lung disease.

After DLT, the original pathological process has little impact on post-operative lung function. Between 6-9 months post-transplant, FEV1, forced vital capacity (FVC) and TLC are generally in the low normal range $[45,63]$ with an average FEV1 of $78-85 \%$ and FVC of $66-92 \%$ predicted $[65,67,69]$.

\section{Exercise performance}

Following LT, there are substantial improvements in exercise capacity. Within the first 3 months post-transplant, a $60-75 \%$ increase in the mean distance walked in 6 min has been reported [45], with a subsequent plateau in performance. Peak oxygen consumption $\left(V^{\prime} \mathrm{O}_{2}\right)$ values in the range of 
$40-60 \%$ predicted have been reported in the first year after HLT, SLT and DLT [39, 46-48, 70]. Maximum symptomlimited incremental cardiopulmonary exercise following uncomplicated SLT or DLT is characterised by: 1) a low maximum $V^{\prime} \mathrm{O}_{2} ; 2$ ) an absence of abnormal gas exchange, ventilatory or cardiac limiting factors; and 3 ) an early onset of the anaerobic threshold [46]. The majority of LT recipients report leg fatigue, rather than dyspnoea, as the reason for terminating maximal exercise, with leg work capacity being a strong predictor of peak exercise performance [71]. Evidence points increasingly to the role of skeletal muscle dysfunction as the most important factor resulting in reduced maximal exercise capacity following LT.

Oxygen saturation generally remains $>90 \%$ in exercising LT recipients [47, 48], and ventilatory function does not appear to limit exercise in most HLT, SLT and DLT recipients in the absence of complications [72].

Following LT, heart rate increases as predicted during incremental exercise and reaches an adequate level $(60-70 \%$ of age-predicted maximum) to meet the demands of the final workload of the exercise test [47, 48]. Cardiac output is generally sufficient to maintain the workloads reached and, thus, cannot explain the early onset of anaerobic threshold and reduced peak $V^{\prime} \mathrm{O}_{2}$ following LT. However, peripheral circulatory parameters may play a role in exercise limitation.

Similar to deconditioned individuals, LT recipients typically show an early onset of the anaerobic threshold at submaximal levels of $V^{\prime} \mathrm{O}_{2}$ [46]. This may indicate either a limitation of delivery of oxygen to the periphery (i.e. a cardiac and/or vascular limitation), or abnormal uptake and use of oxygen at the level of the muscle. As a result, there is greater dependence on anaerobic metabolism for energy, greater production of metabolic byproducts, such as lactate and a decreased ability to buffer and remove these byproducts.

Impaired oxidative capacity of skeletal muscle of LT recipients has been documented in a number of studies, and may be an important factor limiting exercise in these individuals. Skeletal muscle dysfunction may be due to factors related to the pre-transplant condition, severe deconditioning or, alternatively, to immunosuppressant medications [73].

WANG et al. [74] demonstrated that the skeletal muscle of patients following LT had lower proportions of type-I (oxidative) fibres, as well as reduced oxidative enzyme concentrations. This reduction in proportion of type-I fibres and oxidative enzymes is also present pre-transplant and remains low following the procedure, at least in the short term (3 months) [75]. These findings are in line with the consistent observation of reduced maximum $V^{\prime} \mathrm{O}_{2}$ and early anaerobic threshold in lung transplant recipients, and support a possible role for chronic, possibly irreversible, deconditioning as a contributing cause of the impaired oxidative capacity seen in LT recipients.

In keeping with the histological and biochemical changes seen in the skeletal muscle of LT recipients, skeletal muscle metabolism during exercise has also been found to be abnormal. EvANS et al. [70] reported lower resting intracellular $\mathrm{pH}$ of the quadriceps muscle and greater exercise increase in lactate concentration with incremental leg exercise in these individuals. This is associated with a shorter endurance time and lower peak $V^{\prime} \mathrm{O}_{2}$. These findings indicate a greater reliance on anaerobic metabolism, possibly a result of poor oxygen uptake and/or utilisation by the muscle. TIRDEL et al. [76] found evidence for a defect in the ability of the skeletal muscle to take up and utilise oxygen rather than a problem with oxygen delivery in LT recipients, a finding similar to that seen in patients with metabolic myopathies. This suggested that LT recipients have a defect at the level of the mitochondria, which results in a reduced ability for working muscle to extract oxygen. Reduced capacity of the quadriceps to extract oxygen has also been reported in patients with cystic fibrosis [77] and COPD [78] pre- and posttransplant, indicating that muscle dysfunction antedates the transplant and is not completely alleviated in the posttransplant period, once again highlighting the possible role of chronic deconditioning on impaired exercise performance post-transplant.

An additional factor to consider is that LT recipients chronically take a number of immunosuppressive medications that may also impact on muscle function. Cyclosporin, a calcineurin inhibitor, affects the ability of capillaries supplying skeletal muscle fibres to adequately dilate, thereby reducing oxygen delivery to working muscle [70, 79], which could impair the oxidative capacity of exercising muscle. Mitochondrial function may also be impaired in transplant recipients due to a cyclosporin effect on mitochondrial respiration [80, 81]. Corticosteroids can also result in muscle fibre atrophy and abnormalities in muscle fibre shape and size [82]; however, the morphological and biochemical changes associated with chronic corticosteroid use are not the same as those observed following LT, making this an unlikely culprit.

Of interest, recipients of heart [83], kidney [84] and liver transplants [85] have been found to have exercise profiles similar to $\mathrm{LT}$ recipients (reduced maximum $V^{\prime} \mathrm{O}_{2}$, early anaerobic threshold, absence of abnormal ventilatory or cardiac limitations), suggesting a common factor (e.g. immunosuppressive medications) may be responsible for the aerobic impairment.

In patients with COPD, exercise training can result in improvement in the oxidative capacity of the quadriceps muscle, which is associated with a delay in the onset of lactate acidosis and an increase in peak $V^{\prime} \mathrm{O}_{2}$ [86-88]. Hence, one could anticipate that adaptation to training at the level of skeletal muscle should be possible following transplantation with resultant improvements in exercise capacity. Few studies have examined the effects of exercise training following LT. Aerobic exercise training has been shown to result in modest improvements in peak exercise performance in LT [89] and HLT recipients [90], although the subjects remained with significant aerobic impairment post-training. The implications for impaired exercise performance following LT remain unclear, since recipients unquestionably experience substantial improvements in functional capacity and QoL [3]. Nevertheless, identification of factors contributing to exercise limitation is important in order to optimise rehabilitative strategies for these patients.

In conclusion, although LT recipients demonstrate substantial improvements in exercise capacity compared to their pre-transplant condition, significant impairment in exercise capacity persists, largely related to reduced capacity for skeletal muscle oxidative metabolism. Severe chronic deconditioning, as well as drug effects, are probably important contributing factors. Exercise training may provide a means by which skeletal muscle function can be improved in the post-transplant period.

\section{Quality of life and cost effectiveness}

While survival and functional outcome are the two leading measures for assessing the success of $\mathrm{LT}$, improving recipient QoL is certainly another important objective of the procedure. It has even been suggested that for diseases such as COPD, where a survival advantage of LT has been difficult to demonstrate, improving health-related quality of life (HRQoL) is the primary goal of the procedure [16]. There are significant challenges to studying HRQoL, including lack 
of accepted standard definitions and assessment tools, and the limited incidence and survival of LT recipients, which have hindered investigation in this area. The ideal study of HRQoL in LT recipients would survey patients HRQoL longitudinally, include both pre-transplant and post-transplant assessments, involve sample sizes large enough to permit valid subgroup comparisons, and cross reference with all patients' medical data to allow for investigations of potential correlations between changes in HRQoL and factors such as medication changes. Despite these limitations, there is a growing body of literature addressing some HRQoL questions and cost-effectiveness for LT.

Numerous studies have observed improved overall and HRQoL after LT and HLT [91-95], and these gains in QoL tend to be sustained for many recipients, but not surprisingly diminish with the onset of complications, such as BOS $[92,94$, $96,97]$. The largest and most recent study to examine the relationship between HRQoL and onset of BOS by VAN DER BERG et al. [94] illustrates the problems that are inherent in studying HRQoL in LT recipients. In their study, patients were assessed both cross-sectionally and longitudinally beginning at 4 months post-transplantation and, at that time, 79 patients were surveyed, but only 27 completed assessments at 49 months post-transplant. However, the correlation between the cross-sectional and longitudinal studies components of the study, both of which demonstrated a reduction in BOS-related HRQoL, suggests a true association between these events, but does not identify the cause.

In a 2001 study of HRQoL, ANYANWU et al. [95] addressed an equally important question to that of the effect of BOS on HRQoL, by examining HRQoL in SLT, BLT and HLT recipients. These authors utilise the EuroQoL EQ5D questionnaire in a cross-sectional study of 87 pre-transplant and 255 post-transplant patients. The EuroQoL ultimately employs a regression equation to define a health utility value measured on a scale where 0 represents death and 1 the best possible health status. ANYANWU et al. [95] described a mean utility value of 0.31 for patients on the waiting list, 0.61 for SLT, 0.82 for BLT and 0.87 for HLT. These values suggested a higher HRQoL for BLT and HLT recipients over SLT recipients' but the study had significant limitations. Whilst the study by ANYANWU et al. [95] is one of the first studies to address the important issue of potential differences in HRQoL between LT groups, the baseline HRQoL was lower in the SLT recipients prior to transplant in comparison with DLT and HLT recipients, hence, providing for the possibility that the differences in underlying disease, or poorer general health prior to transplant, may have affected both the choice of transplant procedure and the HRQoL differences observed. A longitudinal study that matches cases for underlying disease, disease severity and pre-transplant HRQoL is needed to better understand the effect of SLT versus BLT and HLT on HRQoL.

Overall, reports of $\mathrm{HRQOL}$ in lung recipients posttransplant are favourable, based on two studies, as $\sim 90 \%$ of LT recipients reported satisfaction with their decision to receive $\mathrm{LT}$, and, for many patients, the QoL gained outweighed a potential reduction in longevity [98]. Clearly, more research is justified in this area to better understand specific causative factors affecting HRQoL in LT recipients.

The issue of cost-effectiveness is closely associated with QoL and is important, since the lifetime cost of care for the LT recipient in the USA has been estimated at $\sim \$ 425,000$ by the Washington University Group [98] and confirmed with similar costs at the University of Pittsburgh (Pittsburgh, PA, USA) [99]. Increasingly, investigators have attempted to determine the additional cost per quality-adjusted life year (QUALY) for LT recipients compared with standard care without transplantation. This approach aims to divide the additive costs of LT over standard care by the QUALYs gained by LT [96]. The emerging picture is that the lifetime follow-up of LT patients' results in high costs, but remains cost-effective based on overall QUALYs gained [99-101].

Overall, lung transplant recipients appear to benefit in terms of improved quality of life, but at considerable cost, and further research is justified, especially in view of current efforts to expand the donor pool, which may increase access to the procedure.

\section{References}

1. www.ustransplant.org/csr0704/nat-sum.php?organ=IN\&table $=$ html\&submit=GO. Date last accessed: June 1, 2004.

2. Herve P, Silbert D, Cerrina J, Simonneau G, Dartevelle P. Impairment of bronchial mucociliary clearance in long-term survivors of heart/lung and double-lung transplantation. The Paris-Sud Lung Transplant Group. Chest 1993; 103: 59-63.

3. Hosenpud JD, Bennett LE, Keck BM, Boucek MM, Novick RJ. The registry of the International Society for Heart and Lung Transplantation: eighteenth official report-2001. J Heart Lung Transplant 2001; 20: 805-815.

4. Meyer DM, Bennett LE, Novick RJ, Hosenpud JD. Single versus bilateral, sequential lung transplantation for end-stage emphysema influence of recipient age on survival and secondary end-points. J Heart Lung Transplant 2001; 20: 935-941.

5. Cassivi SD, Meyers BF, Battafarano RJ, et al. Thirteen-year experience in lung transplantation for emphysema. Ann Thorac Surg 2002; 74: 1663-1669.

6. Hadjiliadis D, Davis RD, Palmer SM. Is transplant operation important in determining posttransplant risk of bronchiolitis obliterans syndrome in lung transplant recipients? Chest 2002; 122: 1168-1175.

7. Waddell TK, Bennett L, Kennedy R, Todd TR, Keshavjee $\mathrm{SH}$. Heart-lung or lung transplantation for Eisenmenger syndrome. J Heart Lung Transplant 2002; 21: 731-737.

8. McGregor CG, Jamieson SW, Baldwin JC, et al. Combined heart-lung transplantation for end-stage Eisenmenger's syndrome. J Thorac Cardiovasc Surg 1986; 91: 443-450.

9. Bando K, Armitage JM, Paradis IL, et al. Indications for and results of single, bilateral, and heart-lung transplantation for pulmonary hypertension. J Thorac Cardiovasc Surg 1994; 108: 1056-1065.

10. Ueno T, Smith JA, Snell GI, et al. Bilateral sequential single lung transplantation for pulmonary hypertension and Eisenmenger's syndrome. Ann Thorac Surg 2000; 69: 381387.

11. Stoica SC, McNeil KD, Perreas $\mathrm{K}$, et al. Heart-lung transplantation for Eisenmenger syndrome: early and longterm results. Ann Thorac Surg 2001; 72: 1887-1891.

12. Conte JV, Borja MJ, Patel CB, Yang SC, Jhaveri RM, Orens JB. Lung transplantation for primary and secondary pulmonary hypertension. Ann Thorac Surg 2001; 72: 16731679.

13. Meyer DM, Bennett LE, Novick RJ, Hosenpud JD. Effect of donor age and ischemic time in intermediate survival and morbidity after lung transplantation. Chest 2000; 118: 12551262.

14. Heng D, Sharples LD, McNeil K, Stewart S, Wreghitt T, Wallwork J. Bronchiolitis obliterans syndrome: incidence, natural history, prognosis, and risk factors. J Heart Lung Transplant 1998; 17: 1255-1263.

15. De Meester J, Smits JM, Persijn GG, Haverich A. Lung transplant waiting list: differential outcome of type of endstage lung disease, one year after registration. J Heart Lung Transplant 1999; 18: 563-571.

16. Hosenpud JD, Bennett LE, Keck BM, Edwards E, Novick RJ. Effect of diagnosis on survival benefit of lung 
transplantation for end-stage lung disease. Lancet 1998; 35: 24-27.

17. Hertz MI, Taylor DO, Trulock EP, et al. The registry of the international society for heart and lung transplantation: nineteenth official report-2002. J Heart Lung Transplant 2002; 21: 950-970.

18. Estenne M, Maurer JR, Boehler A, et al. Bronchiolitis obliterans syndrome 2001: an update of the diagnostic criteria. J Heart Lung Transplant 2002; 21: 297-310.

19. Negri J, Dunning J, Sharples LD, McNeil K. Native lung volume reduction following single lung transplantation for emphysema. J Heart Lung Transplant 2001; 20: 177 (abstract).

20. Smith S, Foweraker J, Hamilton D, White J, McNeil K. Impact of antibiotic resistant pseudomonas on the survival of cystic fibrosis patients following heart-lung transplantation. J Heart Lung Transplant 2001; 20: 224 (abstract).

21. Collins J, Hartman MJ, Warner TF, et al. Frequency and CT findings of recurrent disease after lung transplantation. Radiology 2001; 219: 503-509.

22. Schulman LL, Estenne M. Effects of transplantation on lung and exercise physiology. Eur Respir Monograph 2004 (in press).

23. Banner NR, Heaton R, Hollingshead L, Guz A, Yacoub $\mathrm{MH}$. Bronchial reactivity to methacholine after combined heart-lung transplantation. Thorax 1988; 43: 955-959.

24. Glanville AR, Yeend RA, Theodore J, Robin ED. Effect of single respiratory manoeuvres on specific airway conductance in heart-lung transplant recipients. Clin Sci (Lond) 1988; 74: 311-317.

25. Glanville AR, Theodore J, Baldwin JC, Robin ED. Bronchial responsiveness after human heart-lung transplantation. Chest 1990; 97: 1360-1366.

26. Maurer JR, McLean PA, Cooper JD, Chamberlain DW, Grossman RF, Zamel N. Airway hyperreactivity in patients undergoing lung and heart/lung transplantation. Am Rev Respir Dis 1989; 139: 1038-1041.

27. Higenbottam T, Jackson M, Rashdi T, Stewart S, Coutts C, Wallwork J. Lung rejection and bronchial hyperresponsiveness to methacholine and ultrasonically nebulized distilled water in heart-lung transplantation patients. Am Rev Respir Dis 1989; 140: 52-57.

28. Higenbottam T, Jackson M, Woolman P, Lowry R, Wallwork J. The cough response to ultrasonically nebulized distilled water in heart-lung transplantation patients. Am Rev Respir Dis 1989; 140: 58-61.

29. Sanders MH, Owens GR, Sciurba FC, et al. Ventilation and breathing pattern during progressive hypercapnia and hypoxia after human heart-lung transplantation. Am Rev Respir Dis 1989; 140: 38-44.

30. Shea SA, Horner RL, Banner NR, et al. The effect of human heart-lung transplantation upon breathing at rest and during sleep. Respir Physiol 1988; 72: 131-149.

31. Duncan SR, Kagawa FT, Starnes VA, Theodore J. Hypercarbic ventilatory responses of human heart-lung transplant recipients. Am Rev Respir Dis 1991; 144: 126-130.

32. Kimoff RJ, Cheong TH, Cosio MG, Guerraty A, Levy RD. Pulmonary denervation in humans. Effects on dyspnoea and ventilatory pattern during exercise. Am Rev Respir Dis 1990; 142: 1034-1040.

33. Sanders MH, Costantino JP, Owens GR, et al. Breathing during wakefulness and sleep after human heart-lung transplantation. Am Rev Respir Dis 1989; 140: 45-51.

34. Otulana BA, Higenbottam TW, Scott JP, Wallwork J. A possible role for mixed venous blood changes in the hyperventilation of exercise in heart-lung transplant recipients. Chest 1990; 97: 3 Suppl., 88S-89S.

35. Estenne M, Primo G, Yernault JC. Cardiorespiratory responses to dynamic exercise after human heart-lung transplantation. Thorax 1987; 42: 629-630.

36. Robin ED, Theodore J, Burke CM, et al. Hypoxic pulmonary vasoconstriction persists in the human transplanted lung. Clin Sci (Lond) 1987; 72: 283-287.
37. Theodore J, Morris AJ, Burke CM, et al. Cardiopulmonary function at maximum tolerable constant work rate exercise following human heart-lung transplantation. Chest 1987; 92: 433-439.

38. Lisbona R, Hakim TS, Dean GW, Langleben D, Guerraty A, Levy RD. Regional pulmonary perfusion following human heart-lung transplantation. J Nucl Med 1989; 30: $1297-1301$.

39. Gibbons WJ, Levine SM, Bryan CL, et al. Cardiopulmonary exercise responses after single lung transplantation for severe obstructive lung disease. Chest 1991; 100: 106-111.

40. Grossman RF, Frost A, Zamel N, et al. Results of singlelung transplantation for bilateral pulmonary fibrosis. The Toronto Lung Transplant Group. N Engl J Med 1990; 322: 727-733.

41. Levine SM, Jenkinson SG, Bryan CL, et al. Ventilationperfusion inequalities during graft rejection in patients undergoing single lung transplantation for primary pulmonary hypertension. Chest 1992; 101: 401-405.

42. Glanville AR, Theodore J, Harvey J, Robin ED. Elastic behaviour of the transplanted lung. Exponential analysis of static pressure-volume relationships. Am Rev Respir Dis 1988; 137: 308-312.

43. Theodore J, Jamieson SW, Burke CM, et al. Physiologic aspects of human heart-lung transplantation. Pulmonary function status of the post-transplanted lung. Chest 1984; 86: 349-357.

44. Otulana BA, Higenbottam TW, Wallwork J. Causes of exercise limitation after heart-lung transplantation. $J$ Heart Lung Transplant 1992; 11: Suppl. 4, S244-S251.

45. Williams TJ, Grossman RF, Maurer JR. Long-term functional follow-up of lung transplant recipients. Clin Chest Med 1990; 11: 347-358.

46. Levy RD, Ernst P, Levine SM, et al. Exercise performance after lung transplantation. J Heart Lung Transplant 1993; 12: Suppl. 1, 27-33.

47. Williams TJ, Patterson GA, McClean PA, Zamel N, Maurer JR. Maximal exercise testing in single and double lung transplant recipients. Am Rev Respir Dis 1992; 145: 101-105.

48. Miyoshi S, Trulock EP, Schaefers HJ, Hsieh CM, Patterson GA, Cooper JD. Cardiopulmonary exercise testing after single and double lung transplantation. Chest 1990; 97: 11301136.

49. Glanville AR, Burke CM, Theodore J, et al. Bronchial hyper-responsiveness after human cardiopulmonary transplantation. Clin Sci (Lond) 1987; 73: 299-303.

50. Glanville AR, Gabb GM, Theodore J, Robin ED. Bronchial responsiveness to exercise after human cardiopulmonary transplantation. Chest 1989; 96: 281-286.

51. Herve P, Picard N, Le Roy LM, et al. Lack of bronchial hyperresponsiveness to methacholine and to isocapnic dry air hyperventilation in heart/lung and double-lung transplant recipients with normal lung histology. The Paris-Sud Lung Transplant Group. Am Rev Respir Dis 1992; 145: 1503-1505.

52. Rajagopalan N, Maurer J, Kesten S. Bronchodilator response at low lung volumes predicts bronchiolitis obliterans in lung transplant recipients. Chest 1996; 109: 405-407.

53. Guz A, Noble M, Eisele J, Trenchard D. Experimental results of vagal block in cardiopulmonary disease. In: Porter $\mathrm{R}$, ed. Breathing: Hering-Breuer Centenary Symposium. London, Churchill, 1970; pp. 315-329.

54. Davies SF, McQuaid KR, Iber C, et al. Extreme dyspnoea from unilateral pulmonary venous obstruction. Demonstration of a vagal mechanism and relief by right vagotomy. $\mathrm{Am}$ Rev Respir Dis 1987; 136: 184-188.

55. Berglund E, Furhoff AK, Lofstrom B, Oquist L. A study of the effects of unilateral vagus nerve block in a dyspnoeic patient. Scand J Respir Dis 1971; 52: 34-38.

56. Winning AJ, Hamilton RD, Shea SA, Knott C, Guz A. The effect of airway anaesthesia on the control of breathing and the sensation of breathlessness in man. Clin Sci (Lond) 1985; 68: $215-225$. 
57. Altose MD. Assessment and management of breathlessness. Chest 1985; 88: Suppl. 2, 77S-83S.

58. Banner NR, Lloyd MH, Hamilton RD, Innes JA, Guz A, Yacoub $\mathrm{MH}$. Cardiopulmonary response to dynamic exercise after heart and combined heart-lung transplantation. Br Heart J 1989; 61: 215-223.

59. Tapper DP, Duncan SR, Kraft S, Kagawa FT, Marshall S, Theodore J. Detection of inspiratory resistive loads by heartlung transplant recipients. Am Rev Respir Dis 1992; 145: Suppl. 2, 458-460.

60. Noirclerc M, Shennib H, Giudicelli R, et al. Size matching in lung transplantation. J Heart Lung Transplant 1992; 11: Suppl. 4, S203-S208.

61. Otulana BA, Mist BA, Scott JP, Wallwork J, Higenbottam $\mathrm{T}$. The effect of recipient lung size on lung physiology after heart-lung transplantation. Transplantation 1989; 48: 625629.

62. Lloyd KS, Barnard P, Holland VA, Noon GP, Lawrence EC. Pulmonary function after heart-lung transplantation using larger donor organs. Am Rev Respir Dis 1990; 142: 1026-1029.

63. Trulock EP, Cooper JD, Kaiser LR, Pasque MK, Ettinger NA, Dresler CM. The Washington University-Barnes Hospital experience with lung transplantation. Washington University Lung Transplantation Group. JAMA 1991; 266: 1943-1946.

64. Mal H, Sleiman C, Jebrak G, et al. Functional results of single-lung tranplantation for chronic obstructive lung disease. Am J Respir Crit Care Med 1994; 149: 1476-1481.

65. Orens J, Martinez F, Becker F, Deeb M, Christensen P, Lynch J. Cardiopulmonary exercise testing following allogeneic lung transplantation for different underlying disease states. Chest 1995; 107: 144-149.

66. Patterson GA, Maurer JR, Williams TJ, Cardoso P, Scavuzzo M, Todd T. Comparison of outcomes of double and single lung transplantation for obstructive lung disease. J Thorac Cardiovasc Surg 1991; 101: 623-632.

67. Bando K, Paradis I, Keenan RJ, et al. Comparison of coutcomes after single and bilateral lung transplantation for obstructive lung disease. J Heart Lung Transplant 1995; 14: 692-698.

68. Levine SM, Anzueto A, Gibbons WJ, et al. Graft position and pulmonary function after single lung transplantation for obstructive lung disease. Chest 1993; 103: 444448.

69. Williams TJ, Grossman RF, Maurer JR. Long-term functional follow-up of lung transplant recipients. Clin Chest Med 1990; 11: 347-358.

70. Evans AB, Al Himyary AJ, Hrovat MI, et al. Abnormal skeletal muscle oxidative capacity after lung transplantation by 31P-MRS. Am J Respir Crit Care Med 1997; 155: 615621.

71. Lands LC, Smountas AA, Mesiano G, et al. Maximal exercise capacity and peripheral skeletal muscle function following lung transplantation. $J$ Heart Lung Transplant 1999; 18: 113-120.

72. Sciurba FC, Owens GR, Sanders MH, Costantino JP, Paradis IL, Griffith BP. The effect of obliterative bronchiolitis on breathing pattern during exercise in recipients of heart-lung transplants. Am Rev Respir Dis 1991; 144: 131135.

73. Bloomfield SA. Changes in musculoskeletal structure and function with prolonged bed rest. Med Sci Sports Exerc 1997; 29: 197-206.

74. Wang XN, Williams TJ, McKenna MJ, et al. Skeletal muscle oxidative capacity, fiber type, and metabolites after lung transplantation. Am J Respir Crit Care Med 1999; 52 (abstract).

75. Morton JM, McKenna MJ, Carey MF, et al. Reduction sin type I fibre proportions and oxidative enzyme activity in skeletal muscle exist pre- and post-lung transplantation. J Heart Lung Transplant 1999; 160: 57-63.

76. Tirdel GB, Girgis R, Fishman RS, Theodore J. Metabolic myopathy as a cause of the exercise limitation in lung transplant recipients. J Heart Lung Transplant 1998; 17: 1231-1237.

77. Oelberg DA, Systrom DM, Markowitz DH, et al. Exercise performance in cystic fibrosis before and after bilateral lung transplantation. J Heart Lung Transplant 1998; 17: 1104 1112.

78. Systrom DM, Pappagianopoulos P, Fishman RS, Wain JC, Ginns LC. Determinants of abnormal maximum oxygen uptake after lung transplantation for chronic obstructive pulmonary disease. J Heart Lung Transplant 1998; 17: 12201230.

79. Sinoway LI, Minotti JR, Davis D, et al. Delayed reversal of impaired vasodilation in congestive heart failure after heart transplantation. Am J Cardiol 1988; 61: 1076-1079.

80. Hokanson JF, Mercier JG, Brooks GA. Cyclosporine A decreases rat skeletal muscle mitochondrial respiration in vitro. Am J Respir Crit Care Med 1995; 151: 1848-1851.

81. Mercier JG, Hokanson JF, Brooks GA. Effects of cyclosporine A on skeletal muscle mitochondrial respiration and endurance time in rats. Am J Respir Crit Care Med 1995; 151: $1532-1536$

82. Decramer M, de BV, Dom R. Functional and histologic picture of steroid-induced myopathy in chronic obstructive pulmonary disease. Am J Respir Crit Care Med 1996; 153: 6 Pt 1: 1958-1964.

83. Kavanagh T, Yacoub MH, Mertens DJ, Kennedy J, Campbell RB, Sawyer P. Cardiorespiratory responses to exercise training after orthotopic cardiac transplantation. Circulation 1988; 77: 162-171.

84. Kempeneers G, Noakes TD, Zyl-Smit R, et al. Skeletal muscle limits the exercise tolerance of renal transplant recipients: effects of a graded exercise training program. Am J Kidney Dis 1990; 16: 57-65.

85. Stephenson AL, Yoshida EM, Abboud RA, Fradet G, Levy RD. Impaired exercise performance following successful liver transplantation. Transplantation 2001; 72: 1161-1164.

86. Casaburi R, Patessio A, Ioli F, Zanaboni S, Donner CF, Wasserman $\mathrm{K}$. Reductions in exercise lactic acidosis and ventilation as a result of exercise training in patients with obstructive lung disease. Am Rev Respir Dis 1991; 143: 9-18.

87. Maltais F, LeBlanc P, Jobin J, et al. Intensity of training and physiologic adaptation in patients with chronic obstructive pulmonary disease. Am J Respir Crit Care Med 1997; 155: 555-561.

88. Maltais F, LeBlanc P, Simard C, et al. Skeletal muscle adaptation to endurance training in patients with chronic obstructive pulmonary disease. Am J Respir Crit Care Med 1996; 154: Suppl. 2, 442-447.

89. Stiebellehner L, Quittan M, End A, et al. Aerobic endurance training program improves exercise performance in lung transplant recipients. Chest 1998; 113: 906-912.

90. Ambrosino N, Bruschi C, Callegari G, et al. Time course of exercise capacity, skeletal and respiratory muscle performance after heart-lung transplantation. Eur Respir J 1996; 9: $1508-1514$

91. Ramsey SD, Patrick DL, Lewis S, Albert RK, Raghu G. Improvement in quality of life after lung transplantation: a preliminary study. The University of Washington Medical Center Lung Transplant Study Group. J Heart Lung Transplant 1995; 14: 870-877.

92. Gross C, Savik K, Bolman M, Hertz MI. Long-term health status and quality-of-life outcomes of lung transplant recipients. Chest 1995; 108: 1587-1593.

93. TenVergert EM, Essink-Bot ML, Geertsma A, van Enckevort PJ, de Boer WJ, van der BW. The effect of lung transplantation on health-related quality of life: a longitudinal study. Chest 1998; 113: 358-364.

94. van Den Berg JW, Geertsma A, van Der BIJ, et al. Bronchiolitis obliterans syndrome after lung transplantation and health-related quality of life. Am J Respir Crit Care Med 2000; 161: 1937-1941. 
95. Anyanwu AC, McGuire A, Rogers CA, Murday AJ. Assessment of quality of life in lung transplantation using a simple generic tool. Thorax 2001; 56: 218-222.

96. Gross CR, Raghu G. The cost of lung transplantation and the quality of life post-transplant. Clin Chest Med 1997; 18: $391-403$.

97. Lanuza DM, Lefaiver C, Mc CM, Farcas GA, Garrity E Jr. Prospective study of functional status and quality of life before and after lung transplantation. Chest 2000; 118: 115122.

98. Ramsey S, Patrick D, Albert R, Larson E, Wood D, Raghu
G. The cost effectiveness of lung transplantation. Chest 1995; 108: 1594-1601.

99. Gartner SH, Sevick MA, Keenan RJ, Chen GJ. Cost-utility of lung transplantation: a pilot study. J Heart Lung Transplant 1997; 16: 1129-1134.

100. van Enckevort PJ, Koopmanschap MA, TenVergert EM, et al. Lifetime costs of lung transplantation: estimation of incremental costs. Health Econ 1997; 6: 479-489.

101. Anyanwu AC, McGuire A, Rogers CA, Murday AJ. An economic evaluation of lung transplantation. J Thorac Cardiovasc Surg 2002; 123: 411-418. 